\title{
OPTIMIZATION OF ENGINE TRUSS MOUNTING BRACKET
}

\author{
Yadu Krishnan S \\ Professor, Department of Aerospace Engineering, \\ Alliance University, Bangalore, India \\ Athul Krishna, Thency M G \\ Student of Department of Aerospace Engineering, \\ Alliance University, Bangalore, India
}

\begin{abstract}
This paper deals with the topology optimization of the engine mounting bracket. The focus of this study is to reduce the weight of the bracket without compromising the structural characteristics. A small reduction in the weight of each bracket will have a great impact on the overall weight of the aircraft. Solid thinking Inspire is used for static analysis and topology optimization. The results of the von mises stress distribution and the displacement of the actual model and the optimized were compared. With the optimized model of engine mounting bracket, $51.25 \%$ weight reduction is achieved to maintain the same structural behaviour.
\end{abstract}

Keywords: Mounting bracket, Design- optimization, Static analysis, Weight reduction.

\section{INTRODUCTION}

The primary load-carrying structures of an aircraft are longerons, stringers, ribs, spars, and bulkheads. These structures are further supported by splicing, truss structures, brackets, etc. The engine of an aircraft is supported by an engine bracket that transfers the loads to the bulkheads through truss structures and truss mount brackets. Six truss mount brackets are used in aircraft HTT-40(Hindustan Turbo Trainer) engine mounting structure. Out of these six truss mount brackets we have considered the bottom aft RHS bracket for modeling and analyzed for stress and displacement after which is topologically optimized and redesigned.

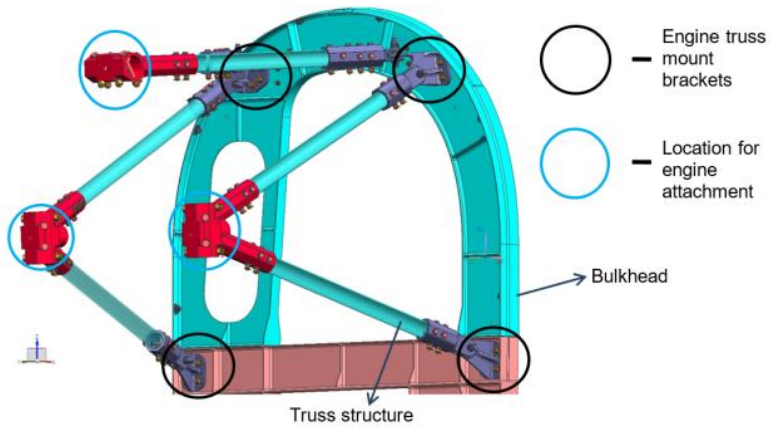

Figure 1: Truss mount bracket of HTT-40
Ishak(2008) discusses the location for an engine mounting bracket so that to minimize the vibration. It discusses that the design of the side member influences the position of the engine mounting bracket. Stress analysis is done for location tests, different thicknesses, and cross-section for the side members using the FEA software called Algor, and Solid work is used for modeling the side members. Five different cross-sections and designs were used for the analysis. This paper also discusses the importance of thickness and design in weight reduction and reducing stress. Nag (2012) presented the ${ }^{1}$ topology optimization using finite element analysis software for the engine accessory components. The main objective of the present work is to minimize the weight of the mount bracket. The main parameter considered for the variation in the behavior of the bracket is its shape. For different shapes, stresses are computed and compared to arrive for the best model under prescribed conditions.

Kirthana et al. (2018) topology optimization of engine mounting bracket of 'Chevrolet beat' using the tools CATIA V5R20 for modeling and Hyper works for finite element analysis. They have analyzed different materials and designs of brackets to optimize the topology. Deshmukh et al. (2015) have performed Static Analysis, model analysis, and harmonic response analysis of engine mounting bracket with the FEA software package ANSYS 15.0. The study shows that the proposed model of engine mount bracket provides $12.5 \%$ weight reduction while maintaining an acceptable level of yield stress and harmonic response.

From these studies we can firmly confirm that the optimization of engine mount bracket is having a great impact on aircraft performance. Careful design of brackets is vital and hence the weight reduction. In the present study is focused on modeling of the existing engine mount bracket and analyze its structural behavior. Maintaining this structural characteristic, the engine mount bracket is redesigned to reduce the weight. The final design of the optimized bracket should have the same structural behaviour and that should not compromise the machining capability. 
International Journal of Engineering Applied Sciences and Technology, 2020

Vol. 5, Issue 2, ISSN No. 2455-2143, Pages 258-263

Published Online June 2020 in IJEAST (http://www.ijeast.com)

II. METHODOLOGY

Siemens NX 10 [3] is designing software that is used for modeling the bracket over other software as it is less complicated and has pretty good features that make our job easy while modeling. In this study, Solid Thinking-Inspire used this software for the Von mises Stress analysis and displacement analysis. This software is also helpful in giving us the optimized model of the workpiece. In each iteration, it can remove the material as much as we require, without sacrificing the characteristics of the original workpiece.

\section{A. Analysis of existing Engine mount Bracket}

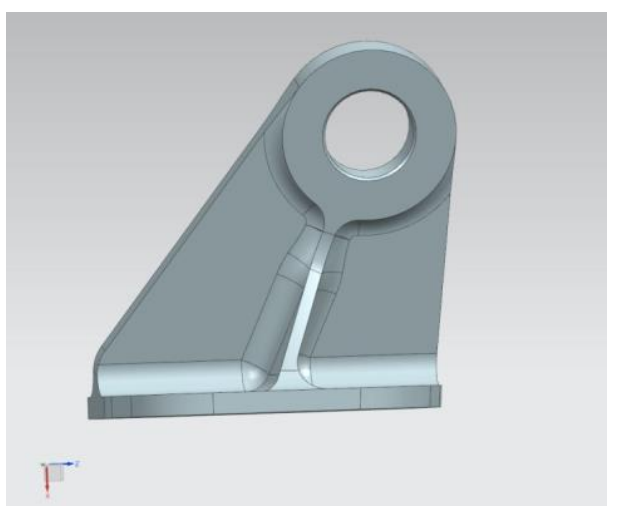

Figure 2: Existing/ Base Model

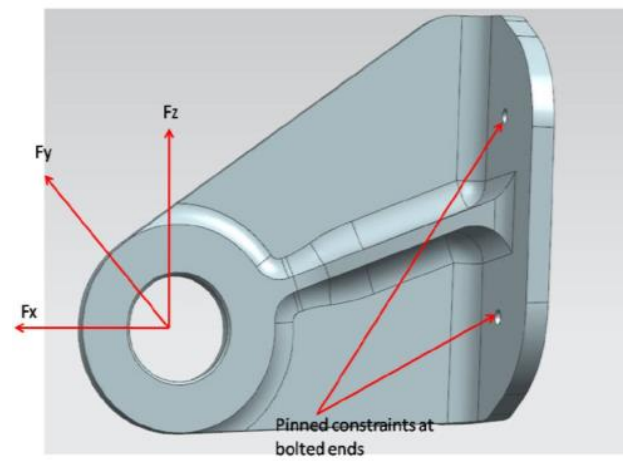

Figure 3: Application of load and boundary conditions

\section{B. Boundary conditions and properties.}

The bracket is bolted to the bulkhead and hence it is constrained for no translation.

There are 20 load cases for an engine, each load case has 3 reactions which are Fx, Fy and Fz, acting at bay end of all six brackets.
Table 1: Material and force parameters

\begin{tabular}{c|c}
\hline Material properties & \\
\hline Material & NCM Steel bar \\
Material spec & BS 5S 99D \\
Yield strength & $1080 \mathrm{MPA}$ \\
Poisson's ratio & 0.29 \\
Density & $7850 \mathrm{~kg} / \mathrm{m}^{3}$ \\
Actual part weight & $0.4533 \mathrm{~kg}$ \\
\hline Reactions at the lug end of the bracket \\
\hline \multicolumn{2}{c}{$\mathrm{F}_{\mathrm{X}}$} \\
$\mathrm{F}_{\mathrm{Y}}$ & $27045.3 \mathrm{n}$ \\
$\mathrm{F}_{\mathrm{Z}}$ & $9670.08 \mathrm{n}$ \\
\hline
\end{tabular}

\section{RESULT AND DISCUSSIONS}

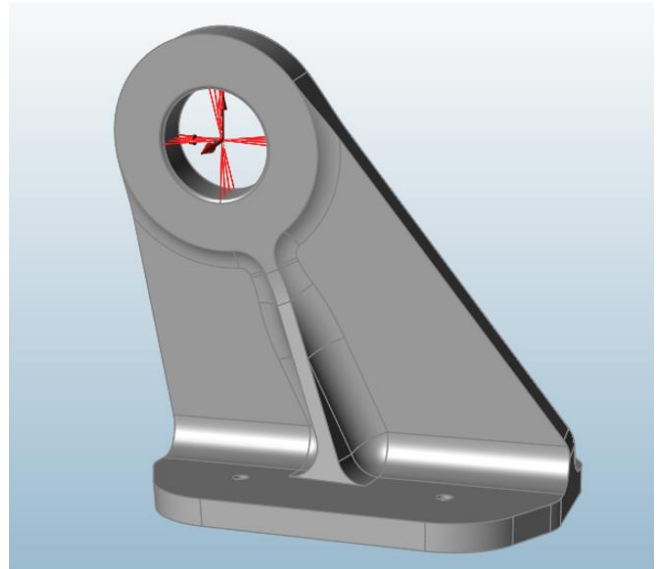

Figure 4: Loads in $\mathrm{X}, \mathrm{Y}$ and $\mathrm{Z}$ direction

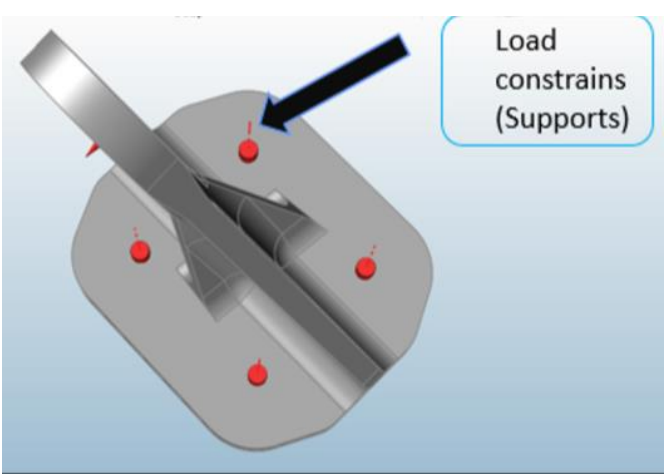

Figure 5: Supports

There are certain constraints are considered, the base part is fixed with supports as shown in the fig and the loads are applied on to the circle part where the engine is to be mounted and the base part has to be attached to the bulkhead, hence there is less scope of weight reduction in those regions

\section{A. Static structural Analysis (base model)}

From the stress analysis, it can be observed that the stress on the bracket is very low when compared to the yield stress i.e. $1080 \mathrm{MPa}$, hence there is scope for the removal of material within the allowable limit such that the stiffness is not affected 


\section{International Journal of Engineering Applied Sciences and Technology, 2020 Vol. 5, Issue 2, ISSN No. 2455-2143, Pages 258-263 \\ Published Online June 2020 in IJEAST (http://www.ijeast.com)}

The max displacement is very less and hence the part can be optimized without increasing the displacement greater than 1 $\mathrm{mm}$. From the fig it is seen that there are lots of regions wherein the material can be removed.

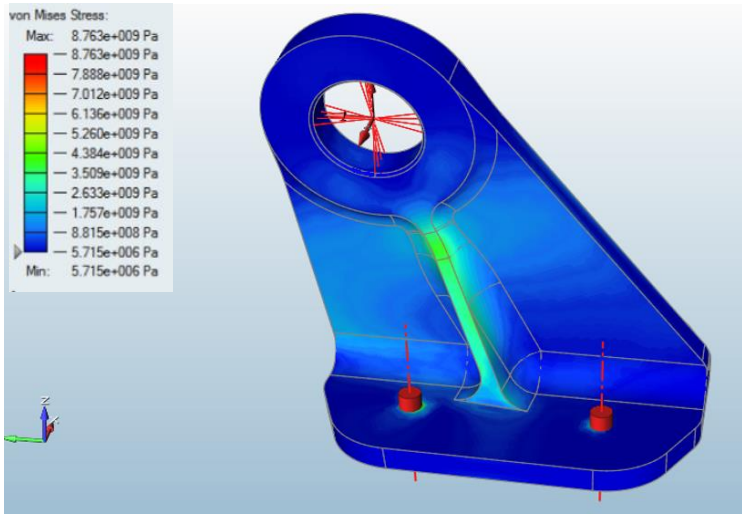

Figure 6 (a): Stress distribution

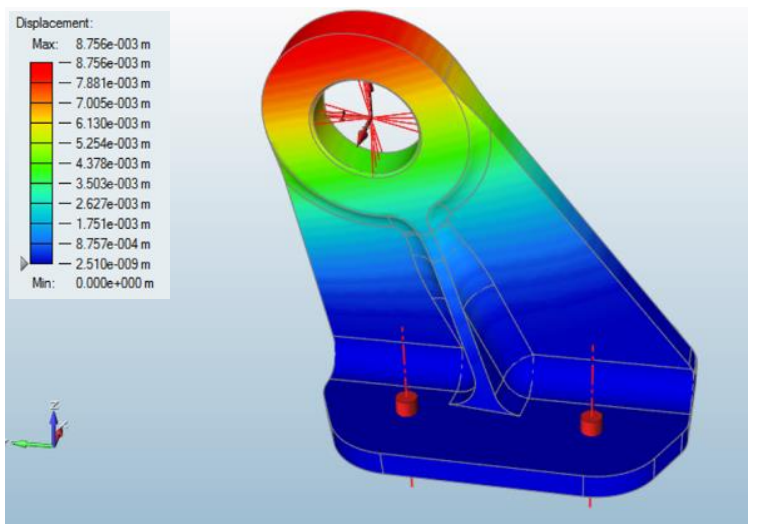

Figure 6 (a): Resultant Displacement -distribution

\section{B. Optimization of Engine Mounting Bracket}

From the basic model, extra mass is added for finding the proper load path during optimization analysis.

The part is divided into

i. Non design space: Space where no optimization can be done. Since the base is attached to the engine bearing and the base region is attached to the bulkhead, no optimization can be done in this region.

ii. Design space: Space where optimization can be done. The region between the boss and the base is not attached to any member hence there is a scope for removal of material in this region.

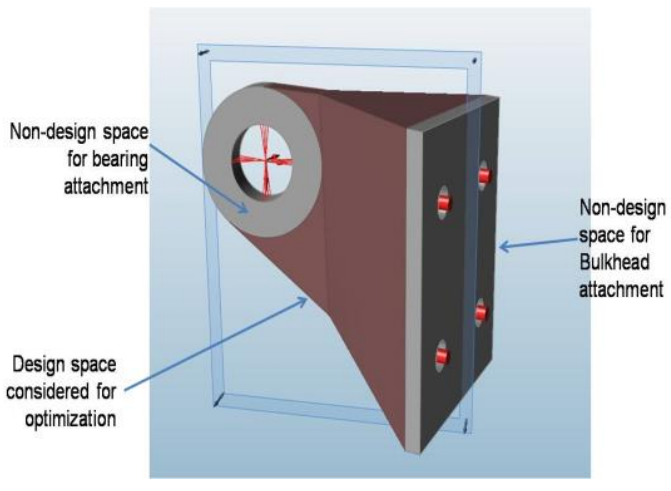

Figure 7: Application of extra material

The modeled part is re-modeled to add extra material since the final shape can be easily manufactured using conventional tools.

\section{Suggested Model:}

Iteration with Mass Target As $10 \%$ with Manufacturing Constraints

The bracket is analyzed for stress and displacement by reducing it to $10 \%$ of its original weight. The results from the analysis are compared with the baseline bracket to arrive at the optimized design space for weight saving.

Manufacturing constrain: It is the process of optimization of material with respect to a given plane such that it can be manufactured by symmetry material removal on either side of the given plane.

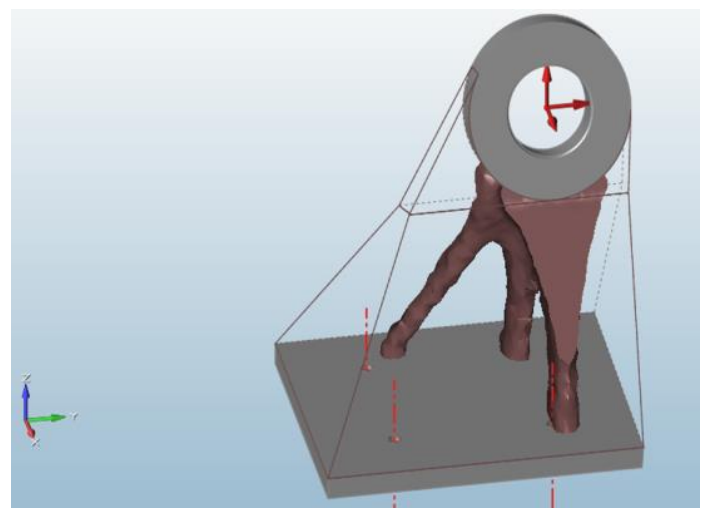

Figure 8: suggested Model 


\section{Static Structural Analysis (suggested model)}

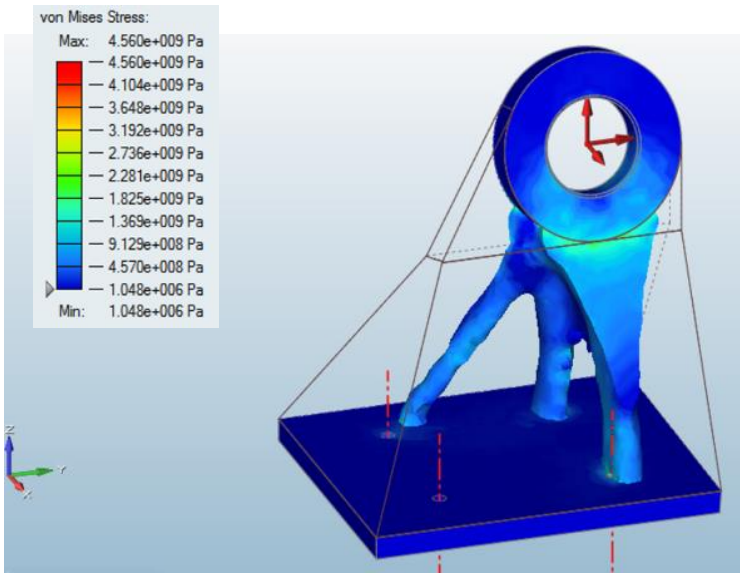

Figure 9 (a): Stress distribution

From the analysis the stress values after optimization is approximately equal to base line structure. weight of the optimized design is found to be $0.078469 \mathrm{Kg}$.

The displacement after optimization is very less when compared to the original bracket, hence the stiffness of the bracket has increased with reduction of weight, thus this is remodelled.

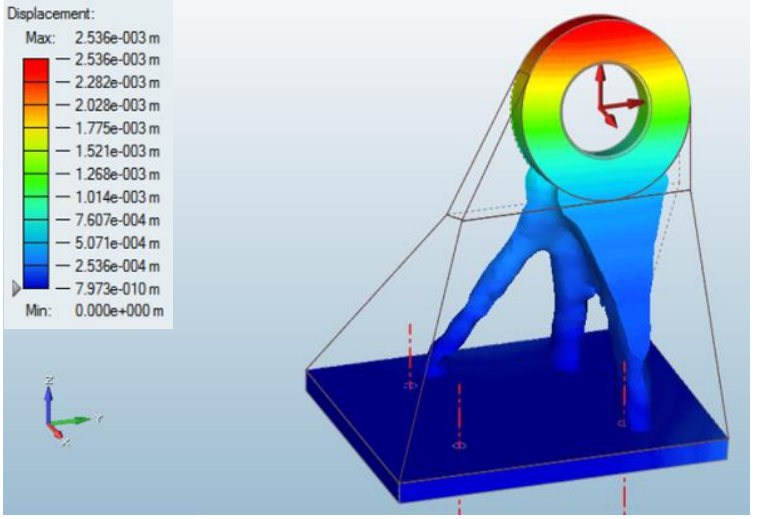

Figure 9 (b): Resultant displacement- distribution

Inference from Inspire Analysis

- The topology shape achieved by 'Inspire' is in accordance with the load path for the given loads and boundary conditions.

- The Load path is from the point of application of load to the points of supports (bolted region of the bracket with the bulkhead).

- The optimized topology cannot be used directly for manufacturing using Machining but can be applied through the 3D printing technology.

- The optimized topology can be used as the basis for modelling the producible part with a similar load path.

\section{E. Final Model}

Since the part obtained after optimization cannot be manufactured by conventional machine tools and in the absence of 3D printer the part must be remodelled such that it can be manufactured by the available conventional tools.

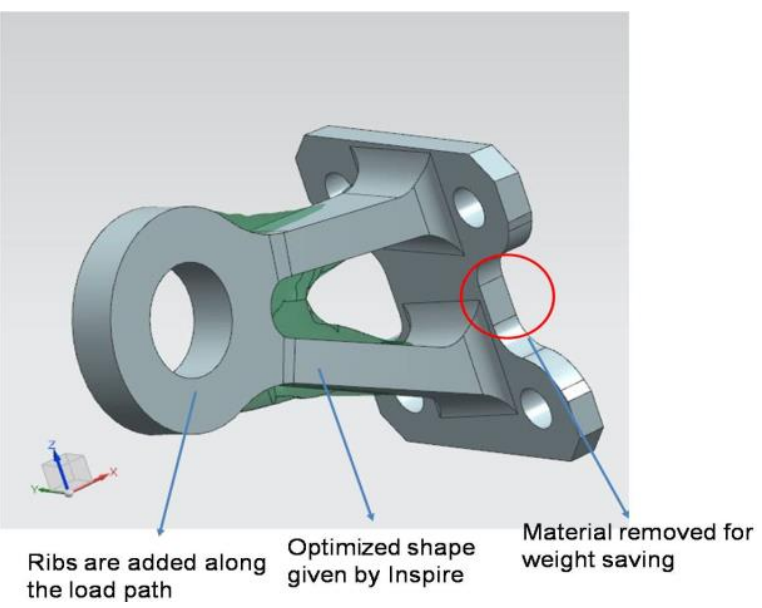

Figure 10: Re-modelled work piece

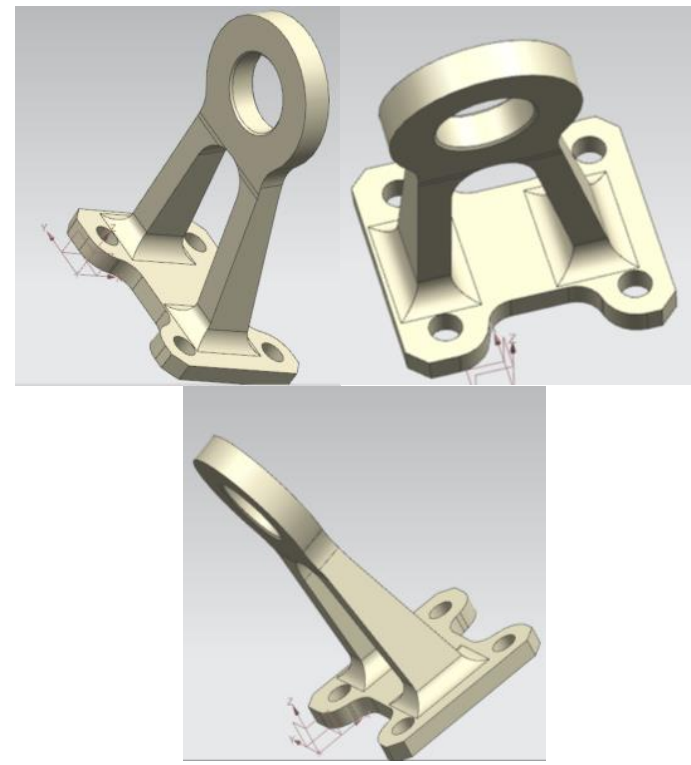

Figure 11: Final model

The workpiece, which has been optimized is again remodeled for the reduction of the materials, that is, to reduce the weight without changing the structural properties of the material. The model is analyzed in Inspire to compare the results with the original model.

\section{F. Static Structural Analysis (final model)}

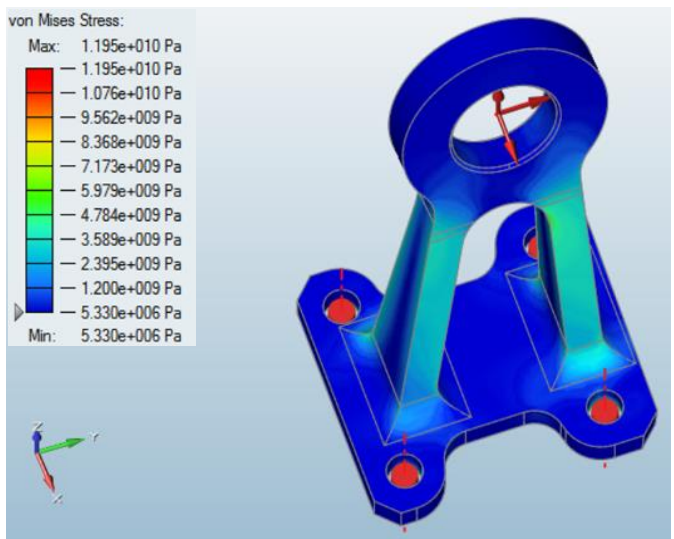


Figure 12 (a): Stress distribution

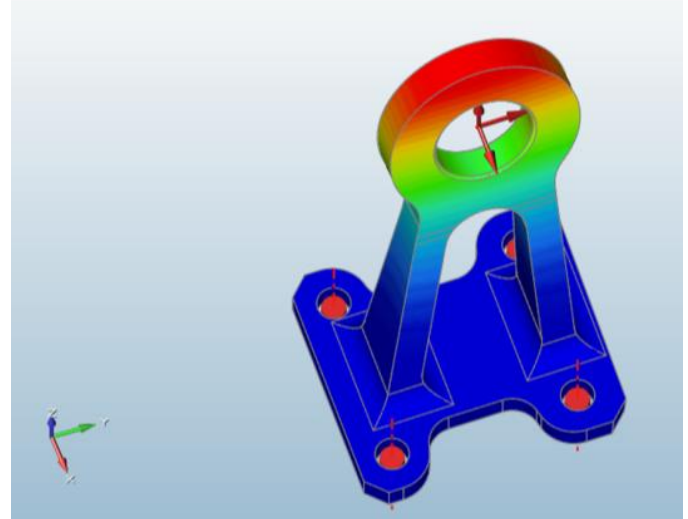

Figure 12 (b): Resultant Displacement distribution

The re-modelled part is again analysed for stress and displacement and is compared with the original part and the values are found to be approximately same.

Table 2: Weight comparison

\begin{tabular}{c|c|c|c}
\hline & $\begin{array}{c}\text { Base } \\
\text { Model }\end{array}$ & $\begin{array}{c}\text { Optimized } \\
\text { model } \\
\text { (final) }\end{array}$ & $\begin{array}{c}\text { Percentage } \\
\text { reduction (\%) }\end{array}$ \\
\hline $\begin{array}{c}\text { Weight } \\
(\text { Kg })\end{array}$ & 0.4533 & 0.22098 & 51.25 \\
\hline
\end{tabular}

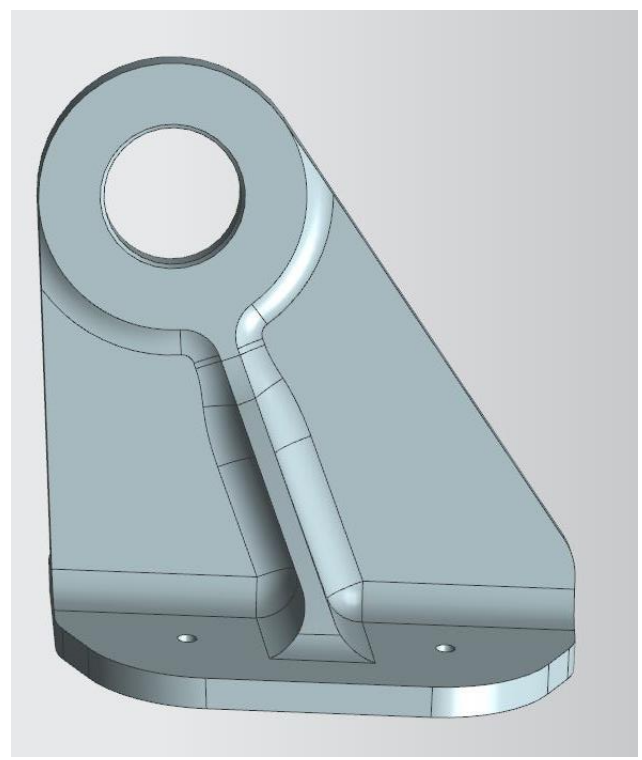

Figure 13(a): Base/ Existing model

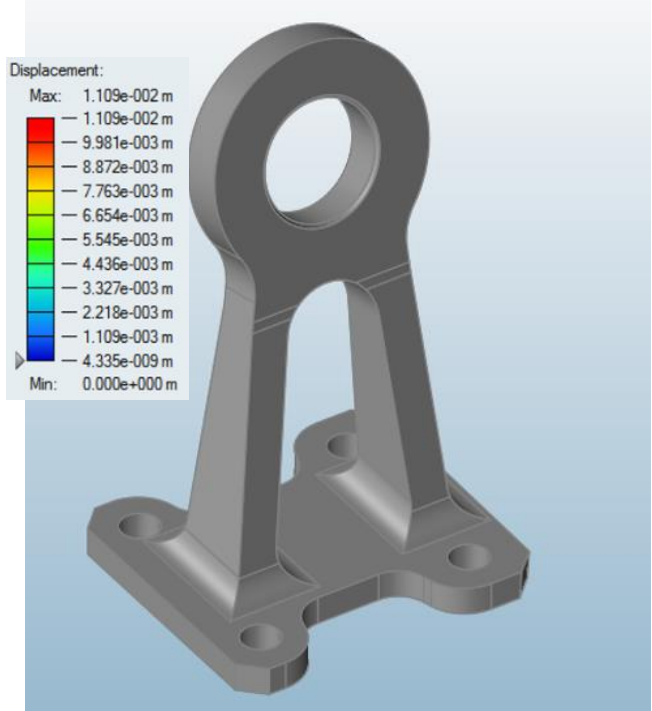

Figure 13(b): Optimized model

IV. CONCLUSION

The study shows that the characteristics of the original workpiece and the re-modeled workpiece are matching. The weight of the original part was $453.3 \mathrm{~g}$, and the weight of the re-modeled part achieved was $220.98 \mathrm{~g}$. The Weight saving achieved on the bracket is $232.32 \mathrm{~g}(51.25 \%)$. A similar design can be implemented to other five brackets supporting the engine truss members. Henceforth, considering all the 6 engine mount brackets of HTT-40 the total weight reduced will be almost $1.4 \mathrm{~kg}$, which helps in the reduction of total manufacturing cost which in return reduces overall aircraft cost. So, by achieving a weight reduction of $1.4 \mathrm{~kg}$ for a basic trainer aircraft, just from the optimization of engine mount brackets, it is possible to reduce a large amount of weight for aircraft with higher weight.

\section{REFERENCES}

[1] Ishak, I. (2008). Optimization of engine mounting bracket location (Doctoral dissertation, UMP).

[2] Nag, M. A. (2012). Topology Optimization of Engine Mounting Bracket. In Hyperwork's Technical Conference.

[3] MING, L., Albin, T., \& Krishna, K. (2013). NX 9.0 for engineering design. University of Missouri.

[4] Kirthana, S., \& Nizamuddin, M. K. (2018). Finite Element Analysis and Topology Optimization of Engine Mounting Bracket. Materials Today: Proceedings, 5(9), 19277-19283.

[5] Deshmukh, M., \& Sontakke, K. R. (2015). Analysis and optimization of engine mounting bracket. International Journal of Scientific Engineering and Research (IJSER), 3(5), 131-136.

[6] Doyle, J. F. (2012). Static and dynamic analysis of structures: with an emphasis on mechanics and computer matrix methods (Vol. 6). Springer Science \& Business Media.

[7] Blake, A. (1989). Practical stress analysis in engineering design. CRC Press. 
[8] Mau, S. T. (2012). Introduction to structural analysis: displacement and force methods. Crc Press.

[9] Cecrdle, J. (2015). Whirl flutter of turboprop aircraft structures. Woodhead Publishing.

[10] Mattingly, J.D., Heiser, W.H. and Pratt, D.T., (2002). Aircraft engine design. American Institute of Aeronautics and Astronautics.

[11] Hal-india.co.in. (2020). Aircraft.[online] Available at: https://hal-india.co.in/Aircraft/M 145

[12] Vinchurkar, S. C., \& Khanwalkar, P. M. (2016). FEA and Topology Optimization of an Engine Mounting Bracket. published in 'International Journal of Current Engineering and Technology E-ISSN, 2277-4106.

[13] Pan, X. Y., Zonni, D., Chai, G. Z., Zhao, Y. Q., \& Jiang, C. C. (2007). Structural optimization for engine mount bracket (No. 2007-01-2419). SAE Technical Paper. 